\title{
Fabián Herrero
}

Doctor en Historia por la Universidad de Buenos Aires. Investigador de CONICET (Instituto Ravignani, UBA). Docente en la carrera de Ciencia Política en la Universidad Nacional de Lanús. Ha publicado distintos libros sobre el periodo de la revolución de independencia: Monteagudo. Revolución, independencia, confederacionismo, Buenos Aires, 2005; Constitución y federalismo. La opción de los unitarios convertidos al federalismo durante el primer gobierno de Juan Manuel de Rosas, Buenos Aires, 2006, y Movimientos de pueblo. La politica en Buenos Aires luego de 1810, Buenos Aires, 2007.

\section{Resumen}

El federalismo de Buenos Aires durante la década de 1810 tiene distintos momentos en los que aparece con nitidez, especialmente entre 1815 y 1820 . Sin embargo, no se ha prestado suficiente atención sobre los discursos que lo combaten desde las posiciones de poder. Esos discursos forman una estela que en este trabajo denomino antifederalismo y que remiten a distintas cuestiones, la distribución de los empleos, la cuestión de la sede capital o la política sobre las jurisdicciones territoriales. En el presente estudio indago esa línea discursiva antifederalista a partir de la tribuna que ofrece la prensa local.

Palabras clave:

Federalismo, antifederalismo, revolución, poder-partidos.

Fecha de recepción: agosto de 2008
Fecha de aceptación:

abril de 2009 


\title{
Anti-federalist Scenarios: \\ Rejecting the Fragmentation of Power and Defending the Leadership of Buenos Aires
}

\author{
Fabián Herrero
}

$\mathrm{Ph}$. D. in History, University of Buenos Aires. CONICET researcher (Instituto Ravignani, UBA). Teaches Political Science in the bachelor's degree program at the National University of Lanús. Has published various books on the period of the Independence revolution: Monteagudo. Revolución, independencia, confederacionismo, Buenos Aires, 2005; Constitución y federalismo. La opción de los unitarios convertidos al federalismo durante el primer gobierno de Juan Manuel de Rosas, Buenos Aires, 2006, y Movimientos de pueblo. La política en Buenos Aires luego de 1810, Buenos Aires, 2007.

\begin{abstract}
During the 1810s, federalism in Buenos Aires experienced various moments when it emerged clearly, particularly between 1815 and 1820 . However, insufficient attention has been paid to the discourse that challenged it from a position of power. This discourse left a trail that I have

various issues, such as the distribution of jobs, the question of the location of the capital and the policy governing territorial jurisdictions. This study explores this anti-federalist, discursive line on the basis of the court provided by the local press.
\end{abstract} called anti-federalism in this study, and involves

Key words:

Federalism, Antifederalism, Revolution, Power-Parties. 


\title{
Escenarios antifederalistas: rechazar la fragmentación del poder y defender el protagonismo de Buenos Aires
}

\author{
Fabián Herrero
}

4 1 federalismo es un componente político fundamental en la realidad política americana. La mayoría de los países de nuestro continente, en algún nivel de su organización de poder, exhiben diferentes variantes de ese signo o la adoptaron en algún tramo de su historia. La situación presente del tema reúne a especialistas que abordan el debate de algunos problemas puntuales. En el caso argentino pueden destacarse someramente varios de ellos. Es de notar, por ejemplo, la llamada dimensión "política-partidaria" que alude, entre otras cosas, a las formas de representación de las provincias, y en esta precisa línea se ha colocado el foco de atención en la relación de los recursos y las elecciones, en donde se intenta examinar lo que se denomina "federalismo electoral y fiscal". El llamado presidencialismo, por otra parte, ha sido destacado como uno de los aspectos constituyentes de nuestra Carta Constitucional basada en los principios federales. Esa idea de concentración del poder se habría reforzado con la última reforma política. El planteo del problema supone que en los últimos años habría una suerte de "presidencialismo absoluto" que niega aspectos republicanos y federales. Otra línea abierta de indagación intenta matizar ese crite- rio que sólo pone el acento en la impugnación, sosteniendo que, esas voces, olvidan estudiar la alternativa política de aquel, la cual también forma parte del problema. Se alude a los gobiernos a los que se los califica de "presidencialismo impotente", esto es, aquellos que no cumplen con el elemental atributo de mando y decisión político. Los finales de gobierno de las administraciones radicales, resultan, en este punto, una muestra incontestable. Una última cuestión se refiere a la fragmentación del poder. Se invoca al federalismo cuando aparece una tendencia de separarse de una provincia o de una región. Este tipo de reclamo político se ha manifestado con distinta fuerza $e$ intensidad tanto en Argentina como en Brasil. ${ }^{1}$

Todos estos temas vinculados con el federalismo no agotan, por cierto, la agenda de problemas actuales. Esa realidad tampoco escapa a la génesis histórica del continente en su periodo de emancipación política en los comienzos del siglo XIX. Uno de los elementos fundamentales remite al tema de la organización del poder.

${ }^{1}$ Nun y Grimson, Nación, 2008. Véanse Botana, "Dilemas", 2008; Abal, "Cuestión", 2008, y Acuña, "Presidencialismo", 2008. 
Como lo ha señalado en un inteligente estudio la investigadora argentina Nora Souto, la nota distintiva entre las tendencias políticas en pugna en el marco del Río de la Plata es la unidad de la soberanía o bien su escisión.

La raíz de la dicotonomía entre los conceptos de unidad y federación, destinada a trascender el ámbito discursivo y plasmarse en los conflictos que agitaron la vida política rioplatense del periodo, abreva en la contrapuesta concepción de la soberanía que entraña una y otra forma de organizar una comunidad política. Mientras que la forma de unidad sostiene que la soberanía es una e indivisible, la de federación admite su segmentación. $^{2}$

Para los lectores no familiarizados con la historia rioplatense de las primeras décadas del siglo XIX, conviene resaltar a grandes rasgos el cuadro político, en donde claramente pueden advertirse esas dos formas de poder: por un lado, hay que mencionar la llamada tendencia centralista que rige los gobiernos porteños (casi sin pausa) desde 1810 hasta 1819, quienes, básicamente, proponen un poder nacional no divisible, esto es, el poder se concentra en un gobierno centralizado en Buenos Aires. Esa forma de poder adquiere distintas siluetas institucionales, juntas, directorios. Por otro lado, la contracara es lo que Halperin Donghi denomina la "otra revolución", ${ }^{3}$ es decir, el federalismo que impulsa el caudillo oriental José Artigas en la Banda Oriental del Uruguay. Como contrapartida, aquí se pone énfasis en la fragmentación del poder nacional, en la escisión

\footnotetext{
${ }^{2}$ Souto, "Unidad/Federación", 2008, p. 175.

${ }^{3}$ Halperin, Revolución, 1972.
}

de la soberanía a partir de una alianza o una confederación. Como puede apreciarse, en este cuadro político inicial el federalismo en Buenos Aires bien puede ser considerado una fuerza competitiva del centralismo (aunque con un peso político indudablemente menor).

Este último tema forma justamente parte de mi tarea de investigación. ${ }^{4}$ Hasta el año 1816 habría dos etapas bien diferenciadas, la primera, que sucede en los primeros años posrevolucionarios, en donde el federalismo es relativamente frágil, la segunda puede ubicarse entre los años 1815 y 1816 , ese signo se presenta ahora como una verdadera alternativa de poder.

En el presente estudio intento continuar mi investigación tratando de analizar el discurso antifederalista. En las páginas que siguen trato de hacer ver cómo, durante esos años, surge en el ámbito de la prensa periódica un discurso de neto corte antifederalista al que no se le ha prestado aún la suficiente atención. En un primer momento analizo el escenario antifederal que se desarrolla en los meses finales del Directorio de Carlos Alvear. En rigor, entre los meses de enero y abril de 1815, el diario El Independiente publica una serie de artículos en donde cuestiona la estela federalista artiguista y las amenazas que un poder de ese signo ocasionaría en Buenos Aires. Posteriormente, describo un momento de transición en donde sobresale un efímero discurso pro federal. En un segundo momento examino el escenario antifederal que se levanta luego de mayo de 1815 (momento en donde se restaura un poder centralista en la ciudad porteña)

${ }^{4}$ Herrero, "Federalistas", 2008. Sobre la cuestión del federalismo y de la soberanía, véanse Chiaramonte, Ciudades, 1997, y Verdo, "Soberanía", 2002. 
hasta la irrupción confederacionista de Buenos Aries en junio de 1816. Varias publicaciones periódicas dedican extensas columnas a cuestionar la posibilidad política de un gobierno "provincialista" o "federal".

Es posible que un análisis de este tipo de intervención política pueda ayudarnos a entender mejor cuál es el punto de vista de las corrientes de opinión que se oponen a la instalación de una fórmula federal en Buenos Aires. ¿Cuestionan a todas las variantes de ese signo por igual o lo hacen con una en particular? ¿Qué aspectos políticos cuestionan? ¿La trama discursiva antifederal surge en un momento preciso, puntual, o mantiene su impulso durante toda la década revolucionaria? Este trabajo tiene como principal objetivo contestar algunos de estos interrogantes en los dos escenarios ya mencionados.

\section{EN EL OCASO DEL DiRECTORIO de Carlos María de Alvear}

Todo parece indicar que "los signos precursores de la conmoción"s que dramáticamente determina la caída del Directorio, se remontan, como lo ha mostrado Juan Canter, a los últimos días del gobierno de Gervasio Posadas. Los síntomas más evidentes y palpables son, sobre todo, la sublevación del Regimiento N. 2 y el levantamiento del Ejército del Norte, en donde directamente no se acata "la designación del nuevo jefe". ${ }^{6}$ En un panorama francamente adverso, es del tode conveniente tener presente que cuando Alvear llega al poder fracasan las tentativas conciliatorias

${ }^{5}$ Canter, "Revolución", s. a., p. 369.

${ }^{6}$ Ibid., pp. 369-370. con Artigas y se produce el desborde de las masas por la campaña. A decir verdad, las provincias están fuera de control. Montevideo es evacuado y tanto Entre Ríos como Corrientes, Santa Fe y, un poco más tarde, Córdoba, declaran su desobediencia a la capital, aceptando el flamante orden promovido por el Protector de los Pueblos Libres. Salta y Jujuy, por su lado, aceptan de buen modo la desobediencia de Rondeau y, paralelamente, Mendoza, produce un movimiento municipal. ${ }^{7}$

En medio de esas jornadas tensas, el federalista Artigas es el fantasma que agita Alvear. Solo él puede disputarle el poder si continúa ganando el oído de las elites provinciales. Para el nuevo representante del Directorio, en un marco de clara descomposición del régimen político que preside, las opciones obviamente se reducen con extrema y dramática rapidez. Parado en medio de un verdadero callejón sin salida no le queda "otro recurso que las armas". ${ }^{8}$ Es de esta manera que finalmente prefiere recorrer un camino que ya ha tomado antes: el de la violencia, el del enfrentamiento militar. Por los caminos entonces de esta convicción, y con un claro fin de uniformar a la opinión, el primer mandatario impulsa la idea de redactar proclamas y circulares tendentes a desprestigiar la figura de Artigas. Con ese propósito, le escribe a Valentín Gómez para que, en su carácter de jefe de la Iglesia, impartiera urgentes órdenes al clero a los efectos de disuadir a la opinión sobre las patrañas circulantes y el peligro que significa el artiguismo. ${ }^{9}$ Un día después, el

${ }^{7}$ Ibid.

${ }^{8}$ Ibid., p. 356.

${ }^{9}$ Esta carta y su contexto puede consultarse en Rodríguez, Historia, 1913, t. II, pp. 215-219. El 11 
ministro Herrera envía una circular señalando los excesos de Artigas, de su hermano Manuel y de Otorgués, así como "su mala fe" y "perversidad". ${ }^{10}$ De su propia pluma, Alvear, por su lado, redacta una proclama contra el líder oriental y sus subalternos. A sus ojos, el denominado Protector de los Pueblos Libres trata "de sublevar a los pueblos contra las autoridades constituidas para introducir en nuestros hogares el desorden y la anarquía sobre la destrucción de todas las bases sociales." 11 También por sugerencia del director, el Cabildo hace pública una proclama contra el caudillo de la otra banda, en donde abundan la denuncia y los agravios: aventurero, enemigo de la prosperidad pública, director de bandidos. $^{12}$

En el marco de todos estos papeles públicos tendentes a desprestigiar a Artigas y al federalismo debe entenderse la serie de artículos, de fuerte tono antifederalista por otra parte, publicados en los números de El Independiente. ${ }^{13}$

de febrero de 1814, un bando del director supremo Gervasio Posadas declaró al líder oriental "infame, fuera de la ley y enemigo de la patria", y además, le puso precio a su cabeza. También se ha destacado que entre 1814 y 1815 hubo ciertos acercamientos entre ambos bandos enfrentados, pero los mismos no llegaron a ningún resultado favorable. Reyes, Bruschera y Melogno, Documentos, 1968-1969, t. II, pp. 309-313.

${ }^{10}$ Canter, "Revolución”, s. a., vol. vI, p. 356.

11 "Proclama de Alvear contra Artigas", Buenos Aires, 31 de marzo de 1815, en Rodríguez, Historia, 1913 , t. II, pp. 127-128.

12 "Proclama del Ayuntamiento contra Artigas", Buenos Aires, 5 de abril de 1815, en Registro Oficial, t. I, pp. 307-308.

13 "Federación", El Independiente, 7, 13 y 21 de marzo de 1815.
El discurso antifederal de El Independiente

La ambigüedad y el misterio, hasta no hace mucho tiempo, rodean a este diario. Bernardo Monteagudo o Manuel Moreno aparecen como los posibles redactores; los fines de su edición no son claros, ya que no se presenta como un órgano de prensa opositor pero tampoco da señales claras de ser un papel oficial. En otro estudio he tratado de probar que los testimonios recogidos en el proceso seguido a los funcionarios que participan del Directorio de Alvear echan luz sobre estas cuestiones. ${ }^{14}$ El testimonio de Manuel Moreno, quien por esos días está a cargo de la Secretaría de Gobierno, es clave. En su declaración sostiene que el que acerca la idea de iniciar esa empresa periodística es justamente Manuel Sarratea desde Londres. Su plan se reduce a un simple argumento que remite al contexto político: es necesario tener "un papel público" en el que se hable "con libertad sobre los desaciertos de Fernando y el estado en el que se halla España", sin que en nada pueda comprometerse "el gobierno con dar entrada de estas especies en su Gazeta Ministerial". ${ }^{15}$ Ese plan se completa con la designación de un redactor, su salario, y el respaldo de la esfera estatal. El hombre apuntado es precisamente Moreno. Su respuesta es inmediata, acepta el cargo y pide 1000 pesos de salario (monto que finalmente no le pagan). El Estado, por su lado, se hace cargo de la impresión y recibe el producto de sus ventas.

Su función no es la de un escritor libre que expresa su voluntad política. Según sus palabras, todo lo que se publica es

${ }^{14}$ Analizo la discusión en torno a quién redactó el diario en Herrero, Monteagudo, 2005.

${ }^{15}$ Ibid., p. 37. 
indicado previamente por los allegados al director del estado y luego de su edición sus artículos son controlados. En una oportunidad uno de esos funcionarios le hizo llegar el reproche de "que el director Alvear le había dicho, que no entendía bien el párrafo sobre Tiranos, y que se lo preguntase al declarante, lo que le bastó para conocer, que estas alusiones no convenían con las ideas del gobierno." 16 Su tarea, entonces, es controlada por los hombres más cercanos al poder como los secretarios Herrera o Monteagudo. Al parecer, estos últimos cumplen la tarea de intermediarios entre el poder directorial y el diario, y son los que en definitiva aclaran las dudas que pueden presentarse a la hora de establecer los términos y el alcance de algún artículo. De este modo, el periódico sigue la línea que baja del más íntimo círculo de poder. Como ya lo habrá advertido el lector, esta lógica política está en perfecta sintonía con lo que señalamos más arriba, Alvear influye directamente en el jefe de la Iglesia, en sus ministros y en el Cabildo para que se expresen contra el líder oriental. Es comprensible entonces que haga lo mismo con el flamante órgano de prensa.

Y si bien esta nueva tribuna de opinión tiene fines que apuntan a la política internacional, no obstante, registra en sus columnas una recurrente línea antifederal, trama discursiva que es necesario comprender y analizar.

\section{Las provincias contra Buenos Aires. Empleos y territorios}

¿Quiénes son los federales y cuáles son sus propósitos? Siguiendo las líneas centrales

${ }^{16}$ Ibid. de la imagen que dibujan algunas de las circulares y proclamas descritas más arriba, podría decirse que son sujetos que tienen fama de hombres duros y poco razonables, y poseen, además, más prontuarios que pergaminos en su vida. Una descripción igualmente negativa puede detectarse también en las columnas de El Independiente. Exactamente, "los que predican la federación, declara su escritor, son unos cuantos ambiciosos, algunos imprudentes, y un corto número de locos". ${ }^{17}$ Pero también están aquellos que alegremente acostumbran subirse a la ola política del momento, sujetos "que por sencillez o por una honesta aunque cándida facilidad se inclinan a las sugestiones de los que ellos creen que son más entendidos". 18 Sus tácticas y sus intenciones son también claras, transparentes. Fomentan el odio en las provincias contra Buenos Aires y cuestionan a la capital, porque esencialmente "se envidian sus recursos: se desea su humillación y hasta su ruina". ${ }^{19}$ Los federales quieren, en fin, que "las provincias se incendien en odios indebidos contra la generosa capital, por cuyos esfuerzos respiran ahora ese aire libre de que gozan". ${ }^{20}$

¿Qué promesas hacen los federales a las provincias? Los federales hacen promesas que en realidad tienen pocos fundamentos. La primera tiene que ver con los empleos que obtendrían las provincias si se cambia de sistema político. "Establecida la federación, sostienen sus agitadores, los naturales de las provincias ocuparán en

17 "Federación", El Independiente, 21 de marzo de 1815.
${ }^{18}$ Ibid.
${ }^{19} \mathrm{Ibid}$.
${ }^{20}$ Ibid., 13 de marzo de 1815 . 
ella exclusivamente los empleos." ${ }^{21}$ Esta propuesta es tan antojadiza como falsa, debido a que con su implementación no lograrían ningún resultado favorable,

a no ser que quieran reducir a Buenos Aires a la clase de una provincia tributaria, en correspondencia de haber dado los primeros pasos en la revolución, será consiguiente que en ella sean excluidos los que pertenecen a las otras. ${ }^{22}$

Dentro de esta perspectiva, se señala que con este tipo de reformas "no se ve que los federalistas vayan a ganar nada”. ${ }^{23}$

Los que hacen este tipo de promesas ligeras olvidan, además, que "el gran cuerpo del Estado que se llama administración o el gobierno, está servido enteramente por individuos que no son hijos de Buenos Aires". ${ }^{24}$ Los que trabajan en la administración estatal provienen de las provincias, los cuales se encuentran distribuidos en las distintas parcelas de la administración. Así, los que ocupan puestos estatales no son porteños, ni "lo son tampoco muchos de los empleados en los demás ramos civiles y en la judicatura: y entre los jefes militares que mandan la fuerza de esta capital tan sólo dos han nacido en ella". 25

La cuestión tiene su historia en Buenos Aires. Desde los primeros años de la revo-

${ }^{21}$ Ibid., 21 de marzo de 1815.

${ }^{22}$ Ibid.

${ }^{23} \mathrm{Ibid}$.

${ }^{24}$ Ibid.

25 "Los naturales de la provincia de Buenos Aires tienen poco o ningún influjo en las resoluciones del gobierno general del estado, y los consejos que este escucha son casi exclusivamente los que suministran los de las provincias que están empleados en la capital." Ibid. lución, los pueblos se quejan porque no se reparten dichos empleos con equidad. Durante 1811, como lo señalé en otro lugar, ${ }^{26}$ se distribuyeron en la ciudad pasquines hostiles al gobierno central, en donde entre otros reclamos se promueve la idea de que los empleos sólo sean ocupados por patricios porteños. Pero también durante el año 1815, justamente en el juicio iniciado a ex miembros del Directorio, se sostiene que Alvear manejó caprichosamente los llamados destinos públicos, acomodando a los miembros de su círculo íntimo en los mejores lugares y cerrando los espacios a otros sectores políticos y sociales. La problemática de los trabajos estatales se repite en cada crisis política. Hay una sensibilidad especial en el tratamiento del tema, en donde desempeñan un papel los abusos y el reclamo de mayor participación a la hora de las designaciones, particularmente en la esfera militar, en la medida en que es dentro de ese ámbito en donde el reparto es realmente considerable. $^{27}$

Otra promesa remite a cortar en seco con la supuesta intención de Buenos Aires de apropiarse de los territorios de otras provincias. ${ }^{28}$ Sin embargo, se señala que ese gobierno "lejos de aumentar su territorio peculiar, lo ha desmembrado y ha establecido en provincias diversas a $\mathrm{Co}$ -

${ }^{26}$ Herrero, "Federalistas", 2008, véase especialmente cap. 3.

${ }^{27} \mathrm{He}$ analizado esta cuestión en mi libro sobre los federalistas de Buenos Aires ya mencionado.

28 "Murmuran igualmente, aunque con bastante reserva, que Buenos Aires, prevalido de la preponderancia de que goza por la eminencia de sus recursos y el crédito de sus armas, medita absorberse a las demás provincias". "Federación", El Independiente, 21 de marzo de 1815. 
rrientes, Entre Ríos y Montevideo que le pertenecían". ${ }^{29}$ Esta idea está en el clima de la época. Es la misma crítica que reciben los que defienden un gobierno federal de tipo nacional fuerte en Estados Unidos, se supone que un Estado más poderoso puede anexar territorios. ${ }^{30}$

En suma, los federales son hombres que siembran el caos y el desorden, mienten respecto a la política de empleos y sobre la política expansionista de Buenos Aires.

Forma de gobierno. ¿Qué proponen los federales y cuáles son sus debilidades?

Suele decirse que la política es un juego. Es un juego hasta que alguien pierde un ojo. Los federales, como se ha visto ya, percibidos como individuos desequilibrados y codiciosos o como aventureros o simples curiosos, juegan con fuego y ciertamente han convertido a la política en un juego altamente peligroso. Sus intentos de reformas han colocado a las provincias de Río de la Plata al borde del enfrentamiento político y militar. Un fósforo (un solo fósforo) mal encendido puede provocar el estallido de un polvorín levantado por estos sectores en el altar de la disciplina pública.

Este perfil de los hombres que levantan las banderas del federalismo esta en perfecta sintonía con el tono con que se presenta su actual proyecto de poder. A juicio del escritor de El Independiente, la cuestión de la definición de la forma de gobierno que debe adquirir el Estado es clave porque de ella depende la vida polí-

\footnotetext{
${ }^{29}$ Ibid.

${ }^{30}$ Morgan, Invención, 2006.
}

tica y social bonaerense, una equivocación (un mal paso) puede ser decisivamente perturbador para el proceso político iniciado en mayo de 1810. El planteamiento, por consiguiente, no puede adquirir otra forma que el drama, debido a que son precisamente unos "locos", unos ambiciosos e imprudentes federales, quienes pretenden modificar el sistema político hasta sus cimientos, desconociendo todo el mal que ello provocaría. En este preciso sentido se sostiene que:

Entre la multitud de maquinaciones con que se pretende extraviar el espíritu público, la más artificiosa es el proyecto de una federación, bajo que quieren constituir desde luego los pueblos unidos, alterando así la forma presente con la cual son administrados y tentando una variación de que esperan el logro de sus pretensiones privadas. Consecuencia de semejante pensamiento es un espíritu de provincialismo tan estrecho, tan iliberal y tan antipolítico que si no acierta a contar en oportunidad, vendrá precisamente a disolver el Estado; y de todas las partes que en la actualidad lo componen no dejará en pie sino secciones muy pequeñas, incapaces de sostenerse por sí mismas, débiles con respecto a los enemigos externos, y mutuamente rivales de su aumento y su gloria por la inmoderación de sus celos. ${ }^{31}$

Varias cuestiones merecen subrayarse. En primer lugar, el pretendido federalismo es un proyecto de desunión nacional, se quiere romper los lazos que ya naturalmente unen a las provincias. Su pretensión primaria y básica es invertir el natural proceso político con el que históricamente

\footnotetext{
31 "Federación", El Independiente, 7 de marzo de
} 1815. 
ese sistema nace y se desarrolla. Lo que no entienden sus partidarios es que "la federación, razona en este sentido el redactor, se ha formado entre pueblos que no estaban unidos antes por otros vínculos, para formar un cuerpo respetable contra los peligros externos". Es así que "no siendo suficientes sus fuerzas particulares para rechazar un tirano, cedieron su independencia individual para juntarse con otras provincias y poder así conjurar la tormenta que les amenazaba". ${ }^{32}$

Desde este supuesto, la perspectiva histórica comparativa le sirve al redactor para justificar el desconocimiento que tienen los federales locales. ¿Cómo surge el federalismo en otros países? Repitiendo casi el argumento que aparece en El Federalista de Norteamérica, sostiene que: "El pueblo de los Alpes (Suiza) y los Estados Unidos de América nos presentan modelos relevantes de una exacta federación." 33 Todo allí tiene una causa y un sentido del cambio. Es que justamente

en ambos países el movimiento contra sus antiguos opresores fue reglado; y el sentimiento de injusticia, uniforme y unísono, determinó a todos sus habitantes a un tiempo a levantarse contra un yugo que todos a una voz conocían no deber soportar. ${ }^{34}$

De ahí que "con esta resolución unánime" se desmoronó abruptamente por todas partes el edificio político que los

${ }^{32}$ Ibid. Sobre la problemática de los poderes públicos, sobre todo la discusión en torno a la concentración del poder y a las ideas de dividirlo, véase el excelente trabajo de Ternavasio, Gobernar, 2007.

33 "Federación", El Independiente, 13 de marzo de 1815.

${ }^{34}$ Ibid. optimía, y "deshechos así los vínculos que ligaban mutuamente a aquellas sociedades, pasaron de acuerdo a imponerse los que prescribe el sistema de la federación". ${ }^{35}$ Es el comienzo de una transición política en el que sin lugar a dudas "ambos pueblos fueron felices" ${ }^{36}$ En suma, en Suiza o en Estados Unidos, por el sendero abierto por la amenaza del poder colonial, cada estado cede oportunamente sus derechos de independencia para unirse en una federación.

Los federalistas locales deben entender que la experiencia de Río de la Plata es diferente. Desde un comienzo, Buenos Aires lidera la revolución y los demás pueblos no tienen un papel en esa liberación. Su incorporación posterior explica por qué la sede central del poder se ubica en terreno porteño y no en otro sitio. ${ }^{37}$

Nuestros pueblos eran regidos por la sola mano de los virreyes: contra estos y el bárbaro sistema colonial se levantó Buenos Aires únicamente, esperando que lo seguirían las demás provincias, pero en realidad sin contar con ninguna combinación que le asegurase esta misma esperanza. Las demás ciudades, aunque oprimidas no menos que la capital, y poseídas acaso de igual deseo de mejorar su condición, no se movieron por entonces, antes fue necesario despachar fuerzas competentes que expulsasen los tiranos territoriales... En estas circunstancias era natural que el gobierno provisional establecido en la capital cuando fue derribado el virrey, se comunicase a las demás provincias a medida que se iban estas libertando, y como el gran cuerpo moral que se llama Estado se iba engrosando progresivamente

${ }^{35} \mathrm{Ibid}$.
${ }^{36} \mathrm{Ibid}$.
${ }^{37} \mathrm{Ibid}$. 
por la sucesiva aglomeración de los pueblo hacia la misma causa, la primera señal de su conformidad era la admisión o reconocimiento de aquel gobierno revolucionario interinamente constituido. Cuanto pudo y ha debido hacerse fue convocar una reunión general de los representantes de todas las provincias, como se ha ejecutado, y a esta Asamblea... es a quien compete fijar los destinos de sus heroicos hijos. ${ }^{38}$

En Buenos Aires en pleno fulgor revolucionario, en contraste con los casos donde surge el federalismo, los pueblos están unidos, uno de ellos se levanta contra el sistema de opresión y los demás se incorporan a esa lucha. Ese esquema de poder, en definitiva, no determina una forma de gobierno federal porque el problema no era que se tratara de provincias o pueblos divididos a los que hay que reunir. La realidad aquí es distinta. Lo que hay es la unión de los pueblos en un sistema de poder liderado por los porteños, y ese sistema no es otro que el de "una república una e indivisible" o "unidad republicana". ${ }^{39}$

Los porteños no están inventando ciertamente nada bajo el sol. Esta perspectiva se vincula al marco histórico de las revoluciones de fines del siglo XVIII. La obsesión revolucionaria de la unidad, como lo ha mostrado Pierre Rosanvallon, tiene una dimensión circunstancial. ${ }^{40}$ Corresponde a un imperativo casi militar en unas provincias amenazadas en sus fronteras por las viejas potencias. En efecto, la unidad es la condición primera de la protección y de la seguridad exterior. Pero lo esencial, realmente, es romper con el antiguo régi-

\footnotetext{
${ }^{38}$ Ibid.

${ }^{39}$ Ibid.

${ }^{40}$ Rosanvallon, Modelo, 2007, p. 28.
}

men y marcar al mismo tiempo la entrada en un nuevo mundo.

Ahora bien, ¿cómo pueden los hombres de la revolución alejarse definitivamente del mundo colonial y combatir a los invasores que levantan las banderas del rey cuando se pretende ir a contramano de un poder de unidad? Los federales, en este sentido, quieren dar varios pasos hacia atrás. Su pretensión de fragmentar el poder destruye cualquier camino exitoso posible. Para decirlo de otro modo

la confederación insinuada es absurda y contraria a sus mismos fines, porque lejos de unir a los pueblos, que debería ser su objeto, los alejará más unos de otros; es antipolítica, porque ataca el vigor del Estado, que bajo la unidad republicana se conserva en un grado más eminente. ${ }^{41}$

Esta es la segunda cuestión sustantiva: se pretende minar los cimientos de un Estado poderoso que hizo la revolución y combate a los enemigos exteriores.

Estos episodios, a los ojos del redactor, señalan con entera claridad "lo perjudicial que sería el adoptar en estos momentos esa federación imprudente que a nosotros se nos propone". 42 A esta altura estamos mejor situados para comprender por qué su principal cuestionamiento es que aquellos que están detrás de semejante proyecto no tienen en claro los más primarios y esenciales ingredientes de su credo político. Por este motivo, se sostiene con notable insistencia que "los federalistas no entienden lo que piden" ${ }^{43}$

41 "Federación", El Independiente, 13 de marzo de 1815.

42 Ibid., 7 de marzo de 1815.

${ }^{43}$ Ibid., 13 de marzo de 1815. 
Pues bien, ¿a qué variante federal se alude con el término federación y por qué con ella se puede disolver el Estado central? Se refieren a lo que estrictamente se conoce como confederación. Justamente, lo que pretenden implementar es "una liga estrecha, formada entre diferentes pueblos o provincias, por medio de la cual constituyen un todo para dar más valor a sus fuerzas." 44 Esta configuración de poder

supone, en fin, una reunión de los votos de cuantos la componen, en un congreso, asamblea, dieta o estados generales, en que se establezcan las leyes que han de regir a todos, se determinen los asuntos de paz y guerra y se impongan las contribuciones con que han de cubrirse los gastos públicos. ${ }^{45}$

De esta manera, lo que se desea instaurar es un nuevo edificio de poder fragmentado. Como sospechará el lector, la forma dramática que adopta el redactor, por otra parte, está en directa relación con que este plan de confederación es el que vienen adoptando las provincias que se adhieren al liderazgo de José Artigas.

El cambio político que se propone desde esa trinchera provoca distintos tipos de problemas y conflictos. Especialmente dos.

Los que han encendido la tea de la discordia no la podrán apagar cuando llegue a incendiar sus casas. Sucesivamente este fuego devorador se propagaría por todas partes, [y todo lleva a que] al fin Buenos Aires tomaría el espíritu de provincialismo que no ha conocido hasta aquí. ${ }^{46}$

\footnotetext{
${ }^{44}$ Ibid., 7 de marzo de 1815.

${ }^{45}$ Ibid.

${ }^{46}$ Ibid., 21 de marzo de 1815.
}

Cuando ese proyecto de poder se ponga en marcha las provincias van a perder elementos vitales. Buenos Aires recostada sobre sí misma ya no tiene ningún tipo de compromiso para enviar "los subsidios" que siempre les ha enviado. Para decirlo de otro modo:

los auxilios que frecuentemente ha despachado con tanta prodigalidad o se suspenderían, o reducirían a la cuota que le cupiese entre los demás pueblos: haría todo lo que pudiese, mas no se sacrificaría: empezaría, por último, a ser de sí misma cuando hasta aquí no lo ha sido sino para otros. ${ }^{47}$

En segundo lugar, provoca dificultades serias en el comercio exterior, "dificultades que no han previsto los amantes de la federación, y que sólo pueden evitarse sujetándose a una autoridad general que establezca los derechos de importación en todos los puertos del Estado". ${ }^{48}$ En un escenario de poder federal

o se haría el contrabando en unos puntos de la federación con perjuicio de otros, o se concederían en unas provincias preferencias indebidas al tráfico extranjero que minorasen los derechos de introducción para atraerse la concurrencia, en cuyo caso otras provincias se verían obligadas a practicar la misma operación, e insensiblemente a fuerza de estas competencias indiscretas los negociantes extranjeros llegarían a no pagar nada, y todo el Estado federal se privaría de estos considerables ingresos. ${ }^{49}$

En suma, a juicio del redactor de $E l$ Independiente hay un proyecto federal en

\footnotetext{
${ }^{47}$ Ibid.

${ }^{48}$ Ibid., 13 de marzo de 1815.

${ }^{49}$ Ibid.
} 
marcha que es preciso desbaratar. Por un lado, ese proyecto esta guiado por actores que son doblemente cuestionados. En primer lugar, por sus perfiles altamente inestables (locos, aventureros) no son sujetos aptos para llevar adelante un gobierno, no son viables políticamente. De ahí que sus ambiciones y fomento del odio son un argumento que justifica el propósito del Directorio de emplear la violencia para combatirlos. En segundo término, esos hombres no conocen el pretendido federalismo que invocan y su aplicación en esos términos equivocados lleva al desastre. Se trata de un nuevo tipo de gobierno que va a romper la unidad nacional, introduciendo, al mismo tiempo, variadas y múltiples reformas negativas: en los empleos del Estado, en la jurisdicción de los territorios, en el comercio exterior y en el subsidio que Buenos Aires le da a las provincias.

El año 1815 es un año de mudanzas. Hay partes del cuadro que, luego de los intensos y agitados días de abril en donde se produce la caída del Directorio, no se ven a simple vista. Bien podría decirse que la dirección de los cambios futuros mal puede adivinarse en el momento de la sublevación militar. $Y$ porque precisamente el rumbo de la revolución es todavía incierto, para obtener una mejor perspectiva histórica, esto es, para entender aquello que no se ve a primera vista, resulta necesario reconstruir y analizar ese inicial escenario político.

\section{BREVE MOMENTO FEDERALISTA}

La administración directorial sucumbe ante la presión ejercida por las fuerzas de las provincias autónomas del Litoral y la Banda Oriental. Es probable que la adhesión al artiguismo se deba sobre todo a que su propuesta resulta ahora más attactiva que la impulsada por las autoridades de Buenos Aires. Por lo menos es lo que expresan los mandatarios de algunas provincias, quienes juzgan abusiva e intolerable su pretensión de mantener sobre ellas una amplia y poderosa supremacía. Frente al fracaso de las estrategias diseñadas por el centralismo porteño, se trata, en efecto, de invertir ese experimento político a partir de la puesta en obra de otra estructura de poder. En esa nueva maquinaria política de corte confederal, cada provincia, al recobrar sus derechos de soberanía y autonomía, puede justamente disponer de más atribuciones (sobre la política, la economía, y el ejército) que las que goza el gobierno nacional.

Desde la caída del llamado "partido fuerte" de Alvear, es palpable que las cosas han comenzado a cambiar. Todo fluye mejor ahora para los que levantan la bandera federal. A los ojos de estos grupos, resulta indudable que el estilo arbitrario del Directorio ha despertado unas furias federalistas que, hasta hace poco tiempo, parecía dormida, sobre todo en territorio bonaerense. Un buen ejemplo de este nuevo giro político que está tomando la cosa pública es la posición adoptada por el comandante militar de Buenos Aires que se ha sublevado en Fontezuelas. Su escrito, dirigido a uno de los comandantes artiguistas, sostiene que son justamente

las mismas razones que han movido al pueblo de Santa Fe para sustraerse de la obediencia del inicuo gobierno de Buenos Aires, recuperando sus derechos [los que] me han movido a mí con toda la división y, de unánime consentimiento con mis oficiales, a no reconocer aquel gobierno mientras se halle 
compuesto de los hombres tiranos e inmorales que oprimen a aquella. ${ }^{50}$

El documento, que lleva las numerosas firmas de sus oficiales, es un síntoma de que ellos tienen esta misma convicción. $Y$ es precisamente en este sentido que se animan a imaginar un único rostro para el horizonte político nacional que es el de "mantener la más estrecha fraternidad y alianza con todos los pueblos libres de las provincias y, que por este acertado camino lo alcance el benemérito de Buenos Aires." 51

El sonido de estas palabras puede oírse también (y casi utilizando los mismos vocablos), en las distintas comunicaciones que emiten al respecto los jefes de los ejércitos de los Andes y del Norte. ${ }^{52}$ En este preciso contexto, el Cabildo porteño reemplaza al Directorio. Esa autoridad, en sin-

50 "Ignacio Álvarez Thomas al comandante de las fuerzas orientales, José Eusebio Hereñú", Fontezuelas, 3 de abril de 1815 en Comisión Nacional, Archivo Artigas (en adelante AA), t. 20, 1974, pp. 295-296. Asimismo, puede consultarse el manifiesto de las tropas de campaña donde explican sus razones por las cuales se sublevan contra Alvear, "Ignacio Álvarez al Cabildo de Buenos Aires”, Fontezuelas, 3 de abril de 1815 en $A A$, t. 20, pp. 298-300. Véase también "Cuartel general del Ejército Libertador en marcha", 14 de abril de 1815 en ibid., p. 301; "Ignacio Álvarez Thomas a Ciriaco Lezica", Fontezuelas, 3 de abril de 1815 en ibid., pp. 302-303.

51 "Ignacio Álvarez Thomas al comandante de las fuerzas orientales, José Eusebio Hereñú" en ibid., pp. 295-296.

52 "Ignacio Álvarez al general José Artigas", Buenos Aires, 18 de abril de 1815 en ibid., t. 20, pp. 330-331. "Resolución adoptada por la Junta de Guerra de los jefes de la guarnición convocada por el coronel mayor José de San Martín, actual gobernador intendente de la provincia de Mendoza", Mendoza, 21 de abril de 1815, en ibid., t. 20, pp. 331-332. tonía con los nuevos tiempos, también toma la palabra. Una de las primeras medidas es la de destruir públicamente el documento que (como ya lo he mencionado) declara al líder oriental enemigo de Buenos Aires. Dicho acto se realiza en una ceremonia solemne que se celebra en la Plaza Mayor. El evento es difundido oportunamente por el diario oficial.

El Cabildo de esta capital, deseando dar a los pueblos un testimonio irrefragable del aprecio que le ha merecido la conducta del general de los orientales don José Artigas, como también la más pública y solemne satisfacción de la violencia con que fue estrechado por la fuerza, y amenazas del tirano [se refiere a Alvear] a suscribir la inicua proclama del 5 del próximo pasado, ultrajante del distinguido mérito de aquel jefe, y de la pureza y sanidad de sus intenciones, no satisfecho con la solemne protesta que contra tan atroz declamación hizo en el manifiesto [redactado por el Cabildo] de 30 del mismo, ha acordado que los ejemplares que existen y conservan en su archivo sin distribuirse, sean quemados públicamente por mano del verdugo en medio de la Plaza de la Victoria en testimonio de la repugnancia que mostró a un paso tan injusto y degradante. ${ }^{53}$

En esta misma línea debe entenderse también el interés del Cabildo porteño

53 "Auto", La Gazeta de Buenos Aires, 27 de mayo de 1815 . Días después se concreta dicha promesa: "se ejecute con auxilio de tropa, asistencia del alguacil mayor, y escribano de este Ayuntamiento, publicándose previamente este auto a toque de caja, y que puesta la diligencia, que acredite su cumplimiento a continuación de este auto, se imprima en La Gazeta para que llegue a noticia del público". "Diligencia de ejecución”, La Gazeta de Buenos Aires, 27 de mayo de 1815. 
por dar a conocer públicamente los distintos mensajes recibidos especialmente desde las provincias del interior. Un aspecto domina esas escrituras felices: claramente manifiestan allí su satisfacción por la caída del ahora "déspota Alvear" y se muestran abiertos a estrechar relaciones amistosas con todas las provincias, incluido el territorio oriental y su jefe. ${ }^{54}$ Repitiendo una lógica histórica, el déspota de hoy es el que ha sido el miembro más importante de las fuerzas legales de ayer, y los subversivos de ayer son los que forman parte de las nuevas fuerzas legales.

Por todo lo dicho hasta aquí, resulta posible suponer que hacia abril de 1815 el gobierno de Buenos Aires parece dispuesto a buscar un acuerdo con el federalismo del litoral. ${ }^{55}$ Para aquellos que han vencido, los pueblos han recobrado sus derechos, quedando Buenos Aires con la intención firme de sostener una alianza con las provincias. Es justamente la postura del Cabildo que ha quedado como la mayor autoridad de la provincia, pero también la de los jefes militares mencionados. Esto es, las máximas autoridades vigentes luego del derrumbe directorial. La reivindicación de vocablos como alianza o de expresiones como la defensa de los "derechos de los pueblos", o bien la de "coalición de provincias" -para aprovechar las palabras usadas por el general San Martín- son un largo y estirado sonido que en todas partes parece sonar poderosa $\mathrm{e}$ inconfundiblemente desde la imaginaria campana de una nueva etapa histórica.

${ }^{54}$ Oficios recibidos en Buenos Aires felicitando al pueblo porteño por la destitución de Alvear. Véase La Gazeta de Buenos Aires, 29 de abril de 1815.

${ }^{55}$ Busaniche, Historia, 1984, p. 362.
Pero ese sonido se deja oír por poco tiempo en Buenos Aires. Distintos historiadores han señalado que si bien ese acercamiento es evidente hay que tener presente que tal estrategia de los sectores centralistas tiene otros fines de los que señalé hasta aquí. Para decirlo con otras palabras, algunos de los gobernantes porteños no actúan con sinceridad, sino que sus actividades públicas tienen como principal finalidad una política de tipo defensivo. Se debe soportar, como una medida política coyuntural, las condiciones impuestas por aquellos que ahora disponen de más poder a lo largo de todo el territorio nacional. De este modo se busca un acercamiento con Artigas, quien ha logrado un poder que, en esos días, ya no se puede ignorar. Por este motivo, no sólo se registran los gestos políticos ya mencionados, sino que también se realizan distintas reuniones para materializar tal alianza. ${ }^{56}$

¿Qué resultado obtienen finalmente con este tipo de política defensiva? Es del todo probable suponer que, por una parte, con su nueva actitud aquellos que gobiernan Buenos Aires logran que el Protector de los Pueblos Libres ya no insista en su amenaza de invasión a esta provincia. ${ }^{57}$

56 "Instrucciones al coronel Elías Galván, coronel Blas José de Pico y doctor Bruno Francisco de Rivarola para el desempeño de sus misiones ante José Artigas. Buenos Aires, mayo de 1815". Instrucciones que servirá de regla (a los mencionados) para negociar y formalizar un tratado de amistad y alianza con los jefes y pueblos de la Provincia Oriental, para lo que se le ha comisionado competentemente en decreto de esta fecha, en Reyes, Bruschera y Melogno, Documentos, 1968-1969, t. II, pp. 350-351.

${ }^{57}$ Artigas comunica, que sus tropas permanecerán dentro de los límites de Santa Fe hasta comprobar el resultado favorable de sus operaciones o, en 
Por otra parte, la paz lograda de manera momentánea resulta sumamente necesaria para definir las futuras estrategias políticas.

En este contexto se entiende por qué hay un acercamiento porteño hacia el artiguismo y por qué es efímero. Después de todo, si bien aquellos que simpatizan con las ideas federalistas, como Soler, ocupan lugares de poder en la provincia, la dirección del gobierno está en manos del grupo centralista. Bien podría decirse que si la revolución de abril se hace con reivindicaciones de corte federalista, en mayo el nuevo gobierno porteño comienza a desplegar una estrategia diferente basada en la centralización del poder. ¿Cuáles son los aspectos salientes de esa estrategia? Buenos Aires forma muy pronto una nueva autoridad con poder de decisión "nacional" (radicada, una vez más, en la ciudad capital), un signo en verdad elocuente de la política centralista. Así, un cuerpo electoral formado por los capitulares más doce electores, elegidos el 19 de abril de 1815, nombra director supremo a Rondeau, quien se encuentra en el Alto Perú. Por esta causa, Álvarez Thomas es rápidamente designado en ese cargo en forma interina.

Simultáneamente se crea una Junta de Observación, cuyos integrantes pertenecen a los sectores notables. La nueva autoridad radica también su sede en la ciudad de Buenos Aires. Su misión principal es la de vigilar la gestión del nuevo ejecutivo. El 5 de mayo esa Junta termina de redactar un estatuto provisional, $y$

caso contrario, en que el gobierno pretenda perpetuarse, unir los esfuerzos para evitarlo. "José Artigas a los oficiales del campamento de Fontezuelas", Paraná, 6 de abril 1815, en AA, t. 20, pp. 309-312. sólo después de aceptarlo, Álvarez Thomas puede asumir el mando político. Este documento reconoce a la propia Junta las funciones de poder legislativo, y a partir de él tanto la Junta como el Cabildo disponen de poderes superiores al del director.

Por otra parte, se anuncia la conformación de una nueva asamblea nacional. Para ello se convoca a un Congreso Constituyente que debe reunirse en la provincia de Tucumán. Una de las instrucciones que reciben los diputados porteños precisa la forma que debe adoptar la nueva configuración de poder, se los invita a que "procuren por cuantos medios estén a sus alcances la indivisibilidad del Estado". ${ }^{58}$ Esto es, en la nueva carta constitucional debe materializarse un poder centralizado, de esta manera de ningún modo el edificio político puede fragmentarse o desmembrarse como reclaman los federalistas. El nuevo director sustituto, por cierto, avala todo este nuevo contexto de matriz centralista. No debe extrañar, entonces, que finalmente el conflicto litoral, localizado básicamente en Santa Fe, retorne a la escena política interprovincial.

Quizá ahora pueda entenderse mejor por qué decía que hay partes en el cuadro político (trazado en abril de 1815) que no se ven fácilmente a primera vista. Muy rápidamente, como acabo de mostrar, Buenos Aires ha tomado un nuevo rumbo que lo separa de la alternativa artiguista y lo inserta, claramente, dentro de esa insistente y obstinada política centralista iniciada en mayo de 1810.

${ }^{58}$ Véase "Instrucciones que la Junta Electoral de la provincia de Buenos Aires da a sus representantes en el futuro Congreso General de todas las provincias de la Unión", en Documentos, 1917, t. vII, p. 43. 
EL CENTRALISMO SE RENUEVA. LA LÍNEA ANTIFEDERALISTA EN LA ESCENA POS-FONTEZUELAS

En el mes de abril de 1815, entonces, aquellos que impulsan la unidad republicana con base en la concentración de poder en Buenos Aires reciben un duro golpe por parte de los sectores que, contrariamente, promueven el sistema confederal o la alianza entre las provincias. Brevemente desde Buenos Aires (muy brevemente por cierto), se apela de forma positiva al federalismo $y$ se tiende un inesperado puente hacia el artiguismo. Sin embargo, un mes después, en mayo, el llamado centralismo político, como un boxeador golpeado, se recuesta en las cuerdas para volver nuevamente a la ofensiva y ocupar el centro del ring.

En este preciso sentido, bien podría decirse que el cuadro político nacional vuelve otra vez a polarizarse: por un lado, la recuperada Buenos Aires con su política de centralización de poder, por otro, las líneas proclives al federalismo que ahora son más complejas y poderosas. En primer término la conocida propuesta de José Artigas y las provincias que adoptaron el federalismo. En segundo lugar, hay que agregar ahora a los federales locales, quienes finalmente hacen un movimiento de pueblo en junio de 1816. ¿Qué proponen? Como forma de gobierno impulsan una nueva configuración de poder confederal republicana y constitucional, recogen el reclamo de las provincias sobre el tema de la capital y, sin precisar dónde debe ubicarse, reconocen que ya no debe instalarse en territorio bonaerense, hay reflexiones sobre el tema de los destinos públicos, esto es, los empleos de la administración pública, y proponen un sistema mixto de elección de representantes donde sin negar la importancia del sistema de representación (comicios electorales) no descartan el empleo de las asambleas populares en casos específicos. ${ }^{59}$ Una nueva agenda política es puesta sobre la mesa pública, muchos de los temas que figuran allí son tomados por la prensa que destina muchas de sus columnas para sospechar de la eficacia de "las reformas" de los federales o provinciales de Buenos Aires. Ese discurso antifederal es el que analizo en las páginas que siguen.

\section{El dilema político, ¿confederación o unidad?}

La tarea de la siguiente asamblea nacional es precisamente resolver un dilema. ¿Cuál? El dilema que se presenta es enunciado en forma de interrogante:

¿De qué sirve haber derribado a los gobernantes corrompidos, estar en posesión de nuestra soberanía radical, y mantener en la memoria futuras felicidades, si entre tanto por falta de unidad se abren mil puertas al enemigo, para que venga a burlarse de nuestra gloria? ${ }^{60}$

Como se ve, las cosas aparecen mezcladas. Por un lado, se duda del destino que pueden tener las unidades provinciales siguiendo con su política extrema de apoyarse sólo en su "soberanía radical" y, por otro, ahora, a diferencia del caso de $E l$ Independiente, surge una línea autocrítica. Los gobiernos centrales han cometido errores. Entre ellos se destacan claramente dos. El primero, es el que se menciona, esas

${ }^{59}$ Analizo esta propuesta confederacionista en Herrero, Movimientos, 2007.

60 "Sin título", El Censor, 26 de octubre de 1815. 
administraciones han aceptado la corrupción como una norma y una costumbre. ${ }^{61}$ El segundo, es que "ninguno de los tales gobiernos ha tenido suficiente legitimidad, no habiendo sido nombrados por el libre y espontáneo sufragio de los pueblos y provincias en que han mandado". ${ }^{62}$ Estos dos aspectos han provocado que los pueblos elaboren una respuesta política que en la hora actual se vive como de puro hecho. Es justamente por "estos antecedentes" que los partidarios del federalismo "deducen la felicidad de haber los pueblos y provincias reasumido su soberanía especial, sacudiendo el yugo de un capitalismo, que tanto les había perjudicado en cinco años de revolución." ${ }^{63}$ Sobre estas convicciones los federalistas consideran que en el presente las provincias, al experimentar el goce de su soberanía, deben nombrar libremente sus diputados para un congreso general en el que todo va a correr por el carril de la legalidad de los actos y la legitimidad de sus miembros. De ahí que de este brilloso acontecimiento sin duda va a surgir un gobierno legítimo que "sepa respetar los derechos peculiares de cada pueblo" y que se interese especialmente en el arreglo de "la administración pública en todos sus ramos, y que sea capaz de dar el más rápido movimiento a todos los resortes del poder de la nación para el logro de su independencia”. ${ }^{64}$

61 "Todo gobierno capital del estado común de estas provincias, que ha regido desde el principio de la revolución, ha sido detestable; ya sea por la corrupción de los gobernantes, que lejos de propender al adelantamiento de los pueblos, sólo han festinado su ruina." Ibid.
${ }^{62}$ Ibid.
${ }^{63} \mathrm{Ibid}$.
${ }^{64}$ Ibid.

Sin embargo, como lo he empezado a insinuar más arriba, si bien desde El Censor se comparten algunas de las críticas a las anteriores administraciones centralistas, la línea de solución propuesta resulta una verdadera amenaza. Los federales no ponen sobre la mesa los defectos que presenta su fórmula política. ¿Cuáles? En una confederación las provincias retienen sus derechos de soberanía y prometen auxiliar a las demás en caso de peligro. La dificultad es que no basta con prometer algún tipo de ayuda en casos extremos, ya que, como se ha visto, esa unión esta en "disolución", y más allá de las buenas intenciones de colaboración mutua, el problema es justamente evitar caer en "un estado sin unidad". ${ }^{65}$ ¿Por qué? Porque sólo un poder central puede mantener unidas a las provincias y actuar con vigor en caso de guerra, como las que se sostienen por estos días.

Otra dificultad también vincula el tema de la capital, esta vez, con la designación de los empleos del estado. El escritor de La Gazeta señala con sorpresa, "oigo decir que salen de Buenos Aires los empleados principales para todas las provincias". ${ }^{66}$ A sus ojos, los federalistas no presentan los hechos correctamente, ya que

de cuatro directores supremos uno solo ha sido de Buenos Aires: en el gobierno de Gervasio Posadas los tres secretarios de Estado eran provinciales, los gobernadores de Cuyo, Córdoba y Tucumán, provinciales.

${ }^{65}$ Ibid.

66 "Federación", La Gazeta de Buenos Aires, 13 de enero de 1816. Véase asimismo, "Espíritu de provincia, capitalismo, porteñistas", en ibid., 11 de marzo de 1816. 
El tema es retomado en una carta enviada a El Censor. ${ }^{67}$ "Ha días que estoy oyendo decir a algunos, sostiene el lector, que es preciso adopte Buenos Aires el espíritu de provincia." ${ }^{68}$ A sus ojos, en esas palabras todo es ruido y huele mal. "Espíritu de provincia, me huele a espíritu de orgullo, espíritu de necedad, espíritu de ignorancia." 69 En este sentido, se pregunta como si no supiera bien lo que está preguntado, "¿querrán decir los vocingleros de tal espíritu o visión que Buenos Aires adopte la diabólica máxima de no dar los empleos de su provincia, sino a los que hubiesen nacido en ella?" $70 \mathrm{El}$ pretendido federalismo está atado a una idea equivocada sobre la designación de los empleos estatales. Esta perspectiva sólo puede ser recorrida por hombres que no están bien de la cabeza y que sólo quieren subirse a la ola de desconcierto para obtener una ventaja. Para decirlo con sus palabras,

pero bajeza no cabe en el caletre de hombres cuerdos, y sí en la de cuatro miserables, que no teniendo con qué vivir o queriendo aumentar sus bienes con lo que sus empleos les producen, fomentan tales rastreras ideas, para que no circule esta clase de lucro sino entre ellos. ${ }^{71}$

Ante cada problema planteado por los federales la solución sigue siendo siempre la misma. La opción es cambiar la orientación de ese espíritu, no se necesita un espíritu provincialista sino un espíritu nade 1816

67 "Artículo comunicado", El Censor, 23 de mayo

${ }^{68} \mathrm{Ibid}$.

${ }^{69}$ Ibid.

${ }^{70}$ Ibid.

${ }^{71}$ Ibid. cional. Como es común en este tipo de exhortaciones las metáforas médicas se mezclan con las religiosas. "Pueblos: no gran ciudad de Buenos Aires, exclama el lector, no permitáis que en vuestro seno se abriguen máximas tan fatales que os introducen la gangrena de la desunión que os consuma." 72 Toda fragmentación es vista como un mal terminal y todo gesto que procure un punto de concentración es percibido como la única respuesta posible. "Espíritu fraternal: espíritu de unidad es lo que necesitáis para terminar la estupenda y difícil obra de vuestra regeneración."73

El trabajo de la revolución es un trabajo de regeneración política, en esa tarea el vocablo fraternidad no es empleado casualmente. Tiene una función política vinculada al nuevo cuadro posrevolucionario en donde se busca recrear los hilos que permitan sabiamente armar un todo. Ese todo que el acontecimiento revolucionario quebró. Como lo ha demostrado Rosanvallon, ${ }^{74}$ la supresión del mundo del antiguo régimen conduce a un movimiento simultáneo de redespliegue de los efectos sociales. El "lazo de cuerpo" que daba su consistencia práctica a la comunidad y que organizaba las representaciones que cada uno tenía de su relación con los otros, en efecto, no puede ser simplemente reemplazado por la afirmación de la pertenencia a un gran todo, aun cuando esta sea magnificada y sublimada en el momento de la fiesta, y en esa ocasión adopte la forma legible. Por esta razón, la índole indefectiblemente más abstracta del nuevo lazo social requiere casi de manera mecánica

\footnotetext{
${ }^{72}$ Ibid.

${ }^{73} \mathrm{Ibid}$.

${ }^{74}$ Rosanvallon, Modelo, 2007, p. 38.
} 
de una contrapartida sensible. De ahí procede la importancia adoptada por la cuestión de la fraternidad durante la revolución. El nuevo contrato social se refuerza con una suerte de "contrato sentimental", ya que el calor de los afectos privados está invitado a contrabalancear la abstracción del lazo de ciudadanía.

En abril de 1815 la palabra fraternidad esta unida a la idea de alianza de los pueblos, ahora es utilizada en relación con la idea de unidad. En uno y en otro casos tiene una función política clara. Se trata de crear lazos afectivos de un todo que se perdió definitivamente en las ruinas del régimen monárquico español y que con una forma de poder o con otra es necesario recrear y consolidar.

$Y$ justamente, en el caso de los antifederalistas, la necesidad de sostener un gobierno de unidad republicana esta asociada a por lo menos dos ideas. La primera es que los federales no quieren esa unidad porque están involucrados en un sistema de creencias cuyos hilos no alcanzan a comprender. Al pretender que las provincias sólo se gobiernen en el propio contorno de su soberanía, no entienden que por ese nuevo sendero se rompen dos logros surgidos en la propia revolución de 1810: la unidad de los pueblos ${ }^{75}$ y la conducción política encabezada por Buenos Aires: ${ }^{76}$ "No, americanos! Apliquemos

75 "Un sistema federal pernicioso en tiempo de guerra, y muy mal entendido por aquellos pueblos, cuyos gobernantes no reconocen un centro supremo a ejemplo de los Estados Unidos de Norteamérica, todas estas causas con otras [...] tienen paralizado ese entusiasmo tan deseado, y aun necesario para nuestra regeneración política." "Artículo comunicado", El Censor, 26 de octubre de 1815.

$$
{ }^{76} \text { Ibid. }
$$

unidos la suma de nuestra energía, y somos libres. Mirad que si falta Buenos Aires, todo el edificio de vuestra quimérica independencia se desploma."

Seguridad nacional: ejército cívico o ejército profesional

Los órganos de prensa de orientación antifederal tienen también sus puntos de disidencia y sus acusaciones cruzadas. El redactor de El Censor sostiene que los vecinos de Buenos Aires han recibido con agrado sus palabras, sin embargo, desde La Gazeta se lo cuestiona porque se cree que apoya el sistema federal. En este sentido, sostiene con ironía que "la bilis fosfórica del editor ministerial no ha tenido la consideración debida a mi celo."78

A sus ojos, lo que no se interpretó bien es que quiso examinar las distintas formas de poder, y entre ellas, claro está, al federalismo, no precisamente para exaltarla sino para tener una mejor perspectiva en la ejecución de la política actual y no tener que repetir errores. En ese marco, se muestra partidario de un sistema centralizado de poder.

El estado de desorden a que nos han arrastrado los pasados errores, es menester calcularlo para obrar con exactitud. Nadie conoce más que yo las ventajas que trae consigo un gobierno único y uniforme en todas sus dependencias. ${ }^{79}$

77 "Pronta ojeada política", El Censor, 26 de octubre de 1815 .

78 "Ilustre pueblo de Buenos Aires", El Censor, 11 de enero de 1816.

${ }^{79}$ Refiriéndose a las tendencias de corte confederal aclara que "nadie es tampoco más opuesto que 
El Censor, por cierto, tiene un momento en donde parece apoyarlos, pero en general no respalda a los federales. Lo que en realidad discuten es sobre algunas cuestiones relativas a la estrategia centralista de poder. Discuten, por ejemplo, sobre cómo debe formarse el ejército.

Bajo la clara inspiración de los artículos de El Federalista, emerge en las páginas de La Gazeta el tema de la seguridad. ¿Qué lectura hacen de los artículos de Hamilton, Jay y Madison? Se recuerda que son textos que combaten "la idea de división de estados". 80 Por ello, los artículos que primeramente aparecen por números en los papeles públicos de Nueva York, intentan mostrar los graves inconvenientes que "resultaron a todas aquellas provincias de adoptar semejante desmembración". 81 Dentro de esta perspectiva, en un primer artículo "sobre federalismo" explican los inconvenientes de establecer una confederación en Estados Unidos. Al no estar unidos, esos estados “están ame-

yo a las subdivisiones peligrosas, que pueden tener lugar. En el mismo Censor citado comparó el funesto aislamiento al despotismo absoluto. Así crea vuestra excelencia que no fue otro mi intento que llamar la atención del gobierno, a fin de que, saliendo del sistema seguido por los anteriores, trille nuevos caminos, que consoliden nuestra independencia, unión y fraternidad. De por consiguiente no ha sido mi idea probar una absoluta necesidad, en cualquier caso del federalismo que se ha introducido, $\mathrm{mi}$ intento ha sido prevenir que se calcule sobre el estado presente, como el único medio de acertar. Para ilustrarnos es menester reunir todos nuestros elementos y ponerlos en acción: es menester amalgamar el espíritu nacional: es menester cooperación armoniosa." "Ilustre pueblo de Buenos Aires", El Censor, 11 enero de 1816.

${ }^{80} \mathrm{Ibid}$.
${ }^{81} \mathrm{Ibid}$. nazados por las potencias extranjeras". ${ }^{82}$ Por su marcado "espíritu de localidad", su posición empeora si su ubicación es lindante "con territorios de dominación extranjera. Necesariamente hay disputas allí y guerras que aparecen en cualquier momento." ${ }^{33}$ Obligados, entonces, a mantener esas permanentes contiendas bélicas, "no podrían contar con el auxilio de las otras, que, al no ser protagonistas "inmediatamente del mal, no querrían concurrir, o lo harían débilmente, a sostener a la provincia que abriese la campaña". 84 No es tarea fácil, además, encontrar "hombres expertos" para las distintas áreas de gobierno dentro de una unidad provincial. $Y$ si bien es posible que algunas sí lo puedan lograr, es difícil que la mayoría pueda alcanzar el mismo objetivo. ${ }^{85}$

Posteriormente, en un segundo artículo titulado "aplicación", con un claro propósito didáctico, se intenta comprender cómo estos inconvenientes, señalados para el caso norteamericano, son perfectamente trasladables a Río de La Plata.

82 Ibid.

${ }^{83} \mathrm{Ibid}$.

${ }^{84}$ Ibid.

${ }^{85}$ Otros puntos señalados son los siguientes: “(8) Cualquiera satisfacción proveniente de un estado fuerte y grande se reciben bien, a un estado pequeño, como que no se respeta, se le exige mil humillaciones y mil sacrificios: este sería el caso con respecto a cada uno de los cuerpos separados de la unión en sus transacciones con las naciones extranjeras. (9) Habría más guerras: la guerra se hace cuando se ve que puede ganarse con ella, y nunca mejor se presenta una apariencia de ello que cuando los estados son débiles, y alterados y disgustados unos con otros, no pueden presentar una defensa respetable." "Sobre federaciones", La Gazeta de Buenos Aires, 30 de marzo de 1816. 
La Banda Oriental lindando con los portugueses, las provincias del Perú con las de Lima, Mendoza con los enemigos de Chile, y Buenos Aires expuesto a las invasiones de ultramar. Véanse aquí una porción de puertas abiertas a la intriga e influencia extranjera, véanse unas cuantas provincias negociando, estipulando, ofreciendo, véanse otras permanecer en la indolencia, y mientras Buenos Aires por ejemplo se hallase expuesto a sucumbir a una invasión española, dormía la Banda Oriental el sueño de la muerte, aletargada por los manejos secretos de los portugueses, o de los españoles mismos, o de lo que es mucho peor todavía por una miserable complacencia en los males de su antigua rival, $¿ Y$ cuál vendría a ser entonces el prospecto de la libertad de los pueblos? Una quimera. ${ }^{86}$

Luego de este sombrío panorama, vuelve sobre El Federalista para señalar la importancia de disponer ejércitos disciplinados o de veteranos. Allí se describe el caso europeo donde, en esos días, una fuerza comparativamente pequeña de tropas disciplinadas, con la ayuda de puestos fortificados, es capaz de impedir y, finalmente, frustrar las empresas de una que sea mucho más considerable. Mirando la realidad de Río de La Plata, se afirma en La Gazeta, este parece ser el modelo a imitar. ${ }^{87}$

En efecto, desde la tribuna del diario oficial se considera que las provincias pueden ser "débiles si se dividen" y, en este sentido, destaca la falta de "seguridad nacional". ${ }^{88}$ Es decir, esos estados no pue-

86 "Aplicación", La Gazeta de Buenos Aires, 30 de marzo de 1816.

${ }^{87}$ Ibid.

${ }^{88}$ Ibid. den sostenerse políticamente por sí mismos. Estos tópicos son cuestionamientos recurrentes en la prensa de Buenos Aires hacia el confederacionismo. ${ }^{89}$ Constituyen preocupaciones permanentes porque responden a una realidad, a sus ojos, amenazada: ¿Cómo hacer frente a la posible invasión, portuguesa o española, desde la defensa de ese suelo en apariencia tan poco sólido que pueden ofrecer unos estados descritos como débiles? ¿Cómo no pensar que los estados pueden separarse definitivamente, más aun, como se recuerda más arriba, hay experiencias recientes en ese sentido, por ejemplo, Paraguay y Banda Oriental?

En la visión de El Censor, el esquema militar tiene que adoptar un esquema más complejo. La propuesta de La Gazeta de formar un ejército de veteranos no cubre ese objetivo. En números anteriores señala que ha intentado "aconsejar que, además del ejército, hubiese una milicia nacional, a imitación de los valientes cívicos de esta capital". Sin embargo, confiesa amargamente que la propuesta no tiene eco en el dominio público local y en poco tiempo "conocí que era mucho pedir". ${ }^{90}$ Esta perspectiva es la que ha pensado "el sabio Mirabeau "en su 'Sisteme Militaire". ${ }^{91}$ En efecto, la instalación de una milicia bien arreglada "es la defensa conveniente,

${ }^{89}$ Refiriéndose a las provincias de Río de la Plata, señala que: "Los enemigos externos no tendrían que atacar a una gran nación, a un pueblo fuerte: sus armas se dirigían alternativamente contra una porción de pequeños estados, debilitados por las discordias, agitados por el odio, y presa de una indiscreta emulación." Ibid.

90 "Ilustre pueblo de Buenos Aires", El Censor, 11 de enero de 1816.

${ }^{91}$ Ibid. 
natural y segura de un gobierno libre". ${ }^{92}$ Una de sus principales ventajas es que en ocasión de una invasión "es el único medio de presentarse al enemigo en todas partes". ${ }^{93}$ El ejército de veteranos debe cumplir otro tipo de función y debe ser convocado "en circunstancias extraordinarias". ${ }^{94}$ Seguramente el punto más fuerte de su argumento es que "la defensa de la patria" no puede ser hecha por cualquier hombre. Únicamente sujetos muy especiales son los que pueden hacerlo con eficacia. Los hombres que están animados sólo por un beneficio económico inmediato o que cumplen ese papel como un trabajo más, no poseen, por cierto, los requisitos esenciales para dar este tipo de batallas. Los indicados son los que defienden valores que estén ligados a su territorio y a su hogar. Esos sujetos son los ciudadanos "porque la propiedad es la que hace a los ciudadanos y el fanatismo de la propiedad es el más ardiente y poderoso de los fanatismos". 95

\section{¿ANTIFEDERALISMO \\ O ANTICONFEDERACIONISMO?}

\section{A MODO DE CONCLUSIÓN}

No hay un solo escenario antifederal sino varios. Y esos escenarios (de los que aquí sólo analizo dos) no están sólo poblados por esas ideas, sino que precisamente constituyen la perfecta contracara de un movimiento federalista poderoso que se plantea como un sector de recambio en el poder. Pasaron los tiempos en que el federalismo

\footnotetext{
92 Ibid.

${ }^{93}$ Ibid.

${ }^{94}$ Ibid.

${ }^{95}$ Ibid.
}

aparece entre retazos. Si bien los cuestionamientos a este núcleo de ideas surgen en los primeros años de la revolución, en ese lapso es difícil encontrar una tribuna de opinión que rechace el federalismo con fuerza y consistencia. Es justamente a partir de 1815 que los partidarios del centralismo deben salir a dar su batalla en el dominio público. Deben, por ejemplo, tolerar a veces la inserción federal, como en abril de ese año, o tienen que sancionar un decreto especial (un indulto) para los porteños que en junio de 1816 deciden invadir la escena política para solicitar reformas de neto corte confederacionista. ${ }^{96}$ Deben, en fin, discutir la agenda política puesta sobre la mesa pública por los federalistas. Los contingentes centralistas deben acomodarse a esa realidad, es por este motivo que salen a escena a confrontar. De ahí que el antifederalismo no se presenta como un discurso permanente durante todo el decenio revolucionario. Sucede en situaciones y en tiempos especiales. Este tipo de manifestación puede advertirse en plena luz pública sólo en momentos en donde el federalismo se instala en el paisaje político como una alternativa de poder.

Pero si esa intervención no se da en cualquier circunstancia, tampoco adopta cualquier forma. Por cierto, no todas las variantes federalistas discuten por igual, sino que lanzan sus dardos políticos a una en particular. Ni la idea federal de Constant ni el modelo de Estado federal merecen su atención, lo que señalan e impugnan es el sistema confederal y la alianza. ¿Por qué? Por dos razones: primero porque los grupos federales defienden esta idea en particular. No hay ningún mo-

${ }^{96}$ Herrero, Movimientos, 2007. 
vimiento social o agrupación política que alce la bandera de un federalismo constantiano o un federalismo pro Estado federal, en cambio, sí hay manifestaciones concretas a favor de las ideas confederacionistas o aliancistas. En segundo lugar porque esa perspectiva busca fragmentar el poder de un Estado central. Esto es, no viene a retocar o a reformar algunas partes del edificio de poder centralista sino que pretende modificarlo hasta sus cimientos.

Teniendo presente los dos escenarios antifederalistas, en el segundo, el que se desarrolla después de abril de 1815, ¿hay un discurso nuevo, presenta una agenda distinta de críticas, o bien es repetición y exceso de lo mismo? En líneas generales se presentan elementos que parecen integrar una interpretación "codificada". Lo que se critica remite a un conjunto de temas comunes: los empleos, el capitalismo, rechazar la idea de fragmentar el poder, defender el protagonismo de Buenos Aires. No obstante, por los bordes de ese discurso cerrado hay algunas líneas diferentes. $\mathrm{La}$ autocrítica, por ejemplo, dentro del centralismo en relación con su propio desempeño y con su vinculación con los sectores federales. Este aspecto puede estar motivado por dos causas diferentes. Por un lado, parece inocultable, luego de cinco años de revolución, que los distintos fracasos de los gabinetes centralistas tienen un grado de responsabilidad que no puede taparse sólo con palabras. Por otro lado, sirve sin lugar a dudas para justificar el juicio llevado a cabo por esos días a los miembros del Directorio caído.

\section{FUENTES CONSULTADAS}

\section{Hemerografía}

La Gazeta de Buenos Aires, Buenos Aires.

El Censor, Buenos Aires.

El Independiente, Buenos Aires.

\section{Bibliografía}

-Abal Medina, Juan Manuel, "La cuestión del federalismo en la Argentina: las paradojas de un juego complejo" en José Nun y Alejandro Grimson (comps.), Nación y diversidad. Territorios, identidades y federalismo, Edhasa, Buenos Aires, 2008.

-Acuña, Carlos H., "Presidencialismo, federalismo y justicia en la democracia argentina" en José Nun y Grimson Alejandro (comps.), Nación y diversidad. Territorios, identidades y federalismo, Edhasa, Buenos Aires, 2008.

-Botana, Natalio R., "Dilemas políticos y fiscales de la organización federal en la Argentina" en José Nun y Alejandro Grimson (comps.), Nación y diversidad. Territorios, identidades y federalismo, Edhasa, Buenos Aires, 2008.

-Busaniche, José, Historia argentina, Ediciones Solar, Buenos Aires, 1984.

-Canter, Juan, "La Revolución de abril de 1815 y la organización del nuevo Directorio" en Ricardo Levene, Historia de la nación argentina, El Ateneo, Buenos Aires, s. a., vol. vI.

-Chiaramonte, José Carlos, Ciudades, provincias, estados: orígenes de la nación argentina (18001846), Ariel, Buenos Aires, 1997.

-Comisión Nacional, Arcbivo Artigas, Impresores Monteverde y Cía. S. A., Montevideo, 1974, t. 20.

- Documentos para la historia argentina, Sesiones de la Junta Electoral de Buenos Aires (18151820), Facultad de Filosofía y Letras, Buenos Aires, 1917, t. VII. 
-Halperin Donghi, Tulio, Revolución y guerra. Formación de una elite dirigente en la Argentina criolla, Siglo XXI, Buenos Aires, 1972.

-Herrero, Fabián, Monteagudo. Revolución, independencia, confederacionismo, Ediciones Cooperativas, Buenos Aires, 2005. , Movimientos de Pueblo. La política en Buenos Aires luego de 1810, Ediciones Cooperativas, Buenos Aires, 2007. "Federalistas de Buenos Aires. Sobre los orígenes de la política revolucionaria", 2008 (inédito).

-Morgan, Edmund S., La invención del pueblo. El surgimiento de la soberanía popular en Inglaterra y Estados Unidos, Siglo Veintiuno Editores, Buenos Aires, 2006.

-Nun, José y Alejandro Grimson (comps.), Nación y diversidad. Territorios, identidades y federalismo, Edhasa, Buenos Aires, 2008.

-Registro Oficial, Imprenta del Estado, Buenos Aires, s. a.

-Reyes Abadie, Washington, Oscar H. Bruschera y Tabaré Melogno, Documentos de bistoria nacional y americana. El ciclo artiguista, Ediciones de la Banda Oriental, Montevideo, 1968-1969, t. II.

-Rodríguez, Gregorio F., Historia de Alvear, con la acción de Artigas en el periodo evolutivo de la revolución argentina de 1812 a 1816, Mendesky, Buenos Aires, 1913.

-Rosanvallon, Pierre, El modelo político francés. La sociedad civil contra el jacobinismo, de 1789 basta nuestros días, Siglo XXI, Buenos Aires, 2007.

-Souto, Nora, "Unidad/Federación" en Noemí Goldman (ed.), Lenguaje y revolución. Conceptos políticos clave en el Río de la Plata, 1780-1850, Prometeo, Buenos Aires, 2008.

-Ternavasio, Marcela, Gobernar la revolución. Poderes en disputa en el Río de la Plata, 1810-1816, Siglo Veintiuno Editores, Buenos Aires, 2007.

-Verdo, Genevieve, "¿Soberanía del pueblo o de los pueblos? La doble cara de la soberanía durante la revolución de la independencia (18101820)", Andes, CEPIHA, núm. 13, 2002, Salta. 